\title{
A Statistical Index Representing a Gross Feature of Several Climatic Time Series by Hard Limiting
}

\author{
By Masanori B. Okamoto \\ Section of Statistics, Faculty of Economics, Hiroshima University, Hiroshima 730, Japan \\ and Kōsei Iwase \\ Department of Applied Mathematics, Faculty of Engineering, Hiroshima University, \\ Hiroshima 730, Japan \\ (Manuscript received 21 February 1981, in revised form 30 October 1981)
}

\begin{abstract}
An index of gross feature of several climatic time series is given by a total of its hard limiting series obtained by level-crossing to the original time series. Under admitting a weak concordance between the paired hard limiting series, a distinguished cold period "Maunder minimum" or a warm period can be interpreted by the above index series.

For a pair of random variable at any two time points, an unbiased estimator of correlation is given by a certain function of level, under the condition that a pair of random variable follows to a bi-variate normal distribution with known mean values and variances. An optimum level for the estimation of correlation is discussed by the criterion of minimum variance under the statistical optimality condition; the variance of estimator is explicitly given by a function of such a bi-variate correlation and level of crossing.

Autocorrelation of index series can be also expressible by an integral form which is a function of such a correlation and level of crossing.
\end{abstract}

\section{Introduction}

In a statistical study of climatic change many different kinds of climatic time series are compared. The set of these time series usually contains sunspot numbers, tree-rings, isotope ratios of oxygen, 10 or 50 years average of air temperature, western surface wind, raised bogs, precipitation aomunt averaged for 50 years, water-level change of the lake, index of poor harvest and historical records of river floods, etc. At the first stage of the study a comparison is made only by testing concordance of the occurrence of maxima and minima. However, it is not always easy to detect precisely the simultaneous occurrences of maxima and minima of these time series. At the second stage more sophisticated method of time series analysis such as the computation of spectrum, coherency and phase angle, sometimes model fitting will be made by actual time series. We are aware of the direct use of such sophisticated method which is based on the severe mathematical assumption of stochastic process, because of the present contaminated data of climatic time series.

Let us now resume a characteristic of climatic time series as follows [Kai (1979)];

1. Precision of time scale and of sample data are not always sufficiently better.

2. Determination of time obtained by tree rings is less reliable. Even isotope ratio method has standard error \pm 30 years.

3. Reliable data are air or water temperature. Precipitation amount and wind direction are also reliable.

4. Other climatic elements are indirectly deduced or estimated by the related other factors in many cases.

5. Sample size is not sufficiently large for the use of statistical method of time series analysis (except for sunspot numbers). (1) Comparison of the two time series or more with different sample sizes will make the discrimination difficulty. (2) Comparison of smoothed curves obtained by mutually different smoothing methods is sometimes re- 
quired.

In spite of these uncertainties in statistical aspects of climatological time series, many climatic times series are fundamentally influenced by the changes of solar activity in delay or without delay under the heat balance and the atmospheric circulation on the earth (e.g. Yamamoto (1979), Nemoto and Asakura (1980)). Thus it is desirable to have an index of a gross climatic feature which is representative for several climatic variations.

In this paper we show an index of gross feature of several climatic time series as a total of hard limiting or clipped series which is produced by a crossing-level suitably chosen. Because of the uncertainties of climatic time series, the hard limiting series obtained by level-crossing seems to be enough to represent a gross feature of climatic variation. For this purpose firstly an estimator or autocorrelation is given by using original and its clipped series, for the case in which a pair of observation at the two different time points of the series assumed to be taken from the bi-variate normal population with the known parameters. Secondly the optimum crossing-level is suggested by the criterion of minimum variance of the estimator of autocorrelation for a given pair of observation at two different time points. Thirdly cross-covariance of clipped series is given by an integral function of population autocorrelations for a pair of observation at two different time points of a time series. These results seems not to be included in the recent work given by Inagaki and Kondo (1980), while Kedem (1980) gave an estimator of autocorrelation by hard limiting series in AR (autoregressive) model. Autocovariance of the climatic index is decomposed into two parts; one is a sum of the integral form of autocorrelation of each original time series and other is a sum of the integral form of cross-correlation among its time series. This decomposition holds for sums of its corresponding estimators.

The time series treated in this paper is assumed to be stationary. However, many climatological time series has a trend in general. So the present procedure should be applied to the time series after eliminating the trend. All the climatological time series analyzed in this paper are fortunately nearly stationary or in a small trend even if they are non-stationary. Although a trend causes a deviation of the crossing level from the predetermined level, a possible maximum error in covariance function due to this deviation can be estimated assuming that a trend is linear.

A practical usefulness of the present index in the climatological sense is rather hard to prove. However, comparison with curves of eustasy and cosmic radiation (tree-ring ${ }^{14} \mathrm{C}$ ) given by Fairbridge (1961) is attempted. The variation in time of the index series shows a reasonable match with cosmic radiation curve (tree-ring ${ }^{14} \mathrm{C}$ ) and eustasy curve, while Fairbridge indicates the striking similarity of variation between sunspot curve smoothed to 100-year means and eustasy. Although the index series shows more acute variation due to a short smoothing interval, it reflects the characteristics of original climatic series adopted here. In fact, the index series behaves partly like sunspot curve and partly behaves like tree-ring curve reflecting features of component series of the index series. The reaction of sunspots to climate is not simple; up to a certain sunspot level, there may be a temperature rise, but then a counter oscillation intervenes and a reversal occurs (Fairbridge, 1961). It is desirable to make a climatic indicator no matter how reversal oscillation and its lag exists unless they are not too large. The purpose of the present paper is to make a synthetic climatic indicator from the various climatic time series being inconsistent to the sunspot changes.

\section{Estimator of autocorrelation by hard limiting series}

Let us now show the following modelling for the climatic time series. The $p$-variate series $Z(t)=\left[z_{1}(t), \ldots, z_{p}(t)\right]^{\prime}, t=1,2, \ldots, N$ are considered as the sample observations of the $p$ private stationary normal process $Z(t)=\left[z_{1}(t)\right.$, $\left.z_{2}(t), \ldots, z_{p}(t)\right]^{\prime}, \mathrm{t}=0, \pm 1, \pm 2, \ldots$, where the mean $E[Z(t)]=0$ is assumed generally. In the variance-covariance matrix $\Sigma(h)=\left[\gamma_{i j}(h)\right] ; \gamma_{i j}(h)$ $=E\left[z_{i}(t) z_{j}(t+h)\right]$, cross-covariances $\gamma_{i j}(h)(i \neq j)$ are unknown even if autocovariances $\gamma_{i i}(h)$ are known. Let us consider the observation series by the following transposed matrix $(N \times P)$,

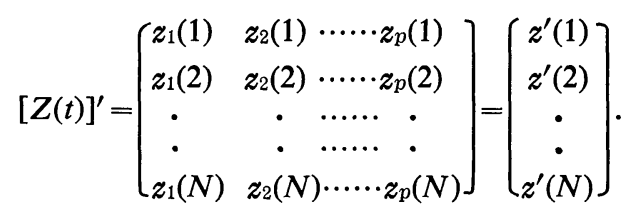

By choosing a suitable level $u$, we get a hard limiting series $C_{u}\left(z_{\alpha}(t)\right)$ from the originally ob- 
tained time series as follows;

$$
C_{u}\left(z_{\alpha}(t)\right)=\left\{\begin{array}{rc}
1 & z_{\alpha}(t)>u \\
0 & \left|z_{\alpha}(t)\right| \leqq u \\
-1 & z_{\alpha}(t)<-u
\end{array}\right.
$$

for non-negative $u$ and $\alpha=1,2, \ldots, p ; t=1,2$, $\ldots, N$. For a fixed $\alpha$ and different two time points of series $t$ and $t+h$, we can assume that $z_{\alpha}(t)$ and $z_{\alpha}(t+h)$ follow to a bi-variate standard normal distribution $N(0,0,1,1 ; \rho)$, since the finite value of variance can be reduced to 1 , without the loss of generality. For a moment we adopt a simple notation $X=z_{\alpha}(t), Y=z_{\alpha}(t+h)$. By denoting hard limiting series $C_{0}\left(z_{\alpha}(t)\right)$ having the crossing level $u=0$ as $\operatorname{sgn}(X)$ where sgn is a symbol sign of $X$, we have

$$
C_{u}(X)=\frac{1}{2}[\operatorname{sgn}(X-u)+\operatorname{sgn}(X+u)] .
$$

Further, we have the next formulation

$$
\operatorname{sgn}(X)=\frac{1}{\pi i} \lim _{\varepsilon \downarrow 0} \lim _{L \rightarrow \infty} \int_{L \geq|t| \geq \varepsilon} \frac{1}{t} \exp (i t x) d t
$$

where $i$ is the imaginary unit of complex number. After some calculation (see Appendix (Lemma 1)), we have

$$
E[X \operatorname{sgn}(Y-u)]=\sqrt{\frac{2}{\pi}} \rho \exp \left(-\frac{1}{2} u^{2}\right)
$$

and

$$
E[X \operatorname{sgn}(Y+u)]=\sqrt{\frac{2}{\pi}} \rho \exp \left(-\frac{1}{2} u^{2}\right) .
$$

Similarly we have the two results as

$$
\begin{aligned}
& E\left[X \cdot C_{u}(Y)\right]=\sqrt{\frac{2}{\pi}} \rho \exp \left(-\frac{1}{2} u^{2}\right), \\
& E\left[Y \cdot C_{u}(X)\right]=\sqrt{\frac{2}{\pi}} \rho \exp \left(-\frac{1}{2} u^{2}\right) .
\end{aligned}
$$

Therefore, the following relation is attainable

$$
\begin{aligned}
\rho= & \frac{\sqrt{2 \pi}}{4} \exp \left(\frac{1}{2} u^{2}\right)\left\{E\left[X \cdot C_{u}(Y)\right]\right. \\
& \left.+E\left[Y \cdot C_{u}(X)\right]\right\} .
\end{aligned}
$$

Thus, if an estimator $\tilde{\rho}$ of the correlation $\rho$ in the bi-variate normal population $N(0,0,1,1 ; \rho)$,

$$
\tilde{\rho}=\frac{\sqrt{2 \pi}}{4} \exp \left(\frac{1}{2} u^{2}\right)\left\{X \cdot C_{u}(Y)+Y \cdot C_{u}(X)\right\}
$$

is adopted for a non-negative $u$, this $\tilde{\rho}$ is unbiased estimator because of $E(\tilde{\rho})=\rho$ from the relation (3).

Secondly let us try to find an optimum crossing- level $u$ in the sense of minimum variance of estimator $\tilde{\rho}$. $\tilde{\rho}^{2}$ contains the terms $X^{2} C_{u}{ }^{2}(Y), X Y$ sgn $(Y-u) \operatorname{sgn}(x-u)$ and the other terms. Now, $E\left[X^{2} C_{u}^{2}(Y)\right], E[X Y \operatorname{sgn}(Y-u) \operatorname{sgn}(X-u)]$ etc., must be evaluated. After algebric process (see Appendix (Theorem 2)), we can obtain the next form of $\operatorname{Var}(\tilde{\rho})$

$$
\begin{aligned}
& \operatorname{Var}(\tilde{\rho})=-\rho^{2}+\frac{\pi}{4} \exp \left(u^{2}\right)+\frac{\sqrt{2 \pi}}{4} \rho^{2} u \exp \left(\frac{1}{2} u^{2}\right) \\
& \quad-\frac{\pi}{2} \exp \left(u^{2}\right) \int_{0}^{u} \frac{1}{\sqrt{2 \pi}} \exp \left(-\frac{1}{2} x^{2}\right) d x \\
& \quad+\frac{1}{4} \frac{1+\rho^{2}}{\sqrt{1-\rho^{2}}} \exp \left(u^{2}\right)\left\{\exp \left(-\frac{u^{2}}{1+\rho}\right)\right. \\
& \left.\quad+\exp \left(-\frac{u^{2}}{1-\rho}\right)\right\}-\frac{1}{4} \rho \exp \left(u^{2}\right) \\
& \quad \times \int_{-\rho}^{\rho} \frac{(1+x)\left(1+x^{2}\right)-2 u^{2}(1-x)(1+2 x)^{2}}{\left(1-x^{2}\right)^{3 / 2}(1+x)} \\
& \quad \times \exp \left(-\frac{u^{2}}{1+x}\right) d x
\end{aligned}
$$

where $|\rho|<1, u \geqq 0$ and for the case when $|\rho|=1$ and $u \geqq 0$

$$
\begin{aligned}
& \operatorname{Var}(\tilde{\rho})=-1+\sqrt{\frac{\pi}{2}} u \exp \left(\frac{1}{2} u^{2}\right) \\
& \quad+\pi \exp \left(u^{2}\right) \int_{u}^{\infty} \frac{1}{\sqrt{2 \pi}} \exp \left(-\frac{1}{2} x^{2}\right) d x .
\end{aligned}
$$

We show the numerical diagram of $\operatorname{Var}(\tilde{\rho})$ for each $\rho=0.0,0.2,0.4$ and 1.0 in Fig. 1, and then

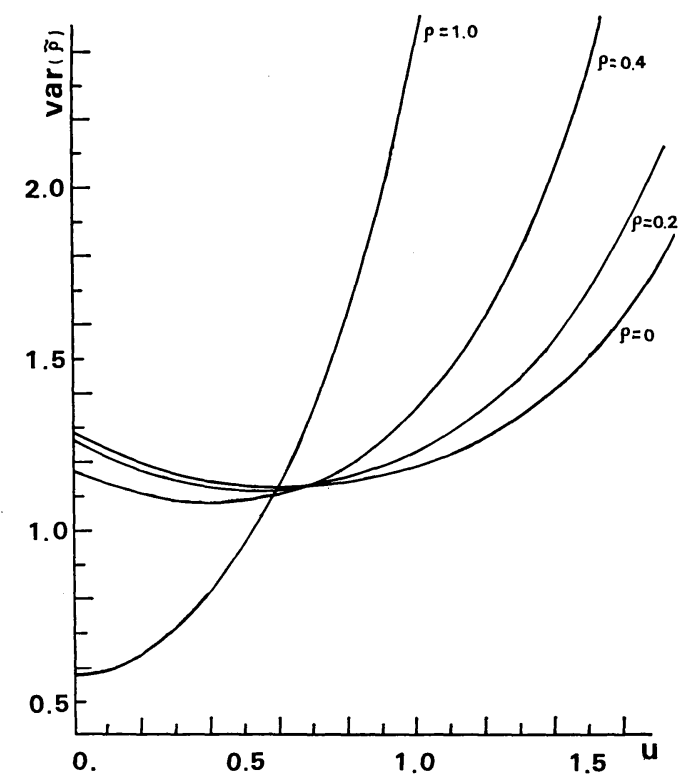

Fig. 1 Var $(\tilde{\rho})$ against $u$ for each population correlation $\rho=0.0,0.2,0.4$ and 1.0 . 


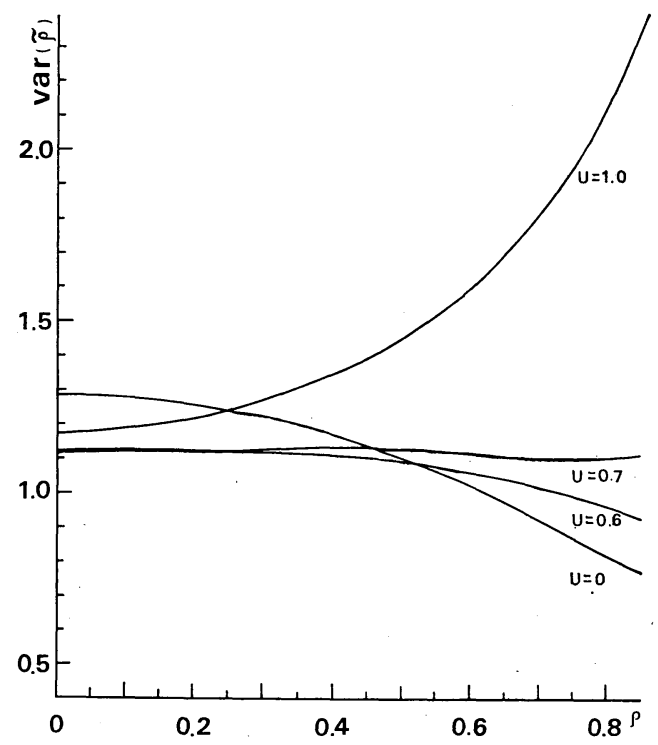

Fig. $2 \operatorname{Var}(\tilde{\rho})$ against $\rho$ for the crossing levels $u=0.0,0.6,0.7$ and 1.0 .

it can be observed that $\operatorname{Var}(\tilde{\rho})$ has a minimum at $u=0.0$ for $\rho=1.0$ and at $u=5 / 8 \sim 2 / 3$ for the small decimal $\rho$ (include zero). It must be noticed that $\operatorname{Var}(\tilde{\rho})$ are nearly constant (about 1.12) for all $\rho$ if the level $u$ is chosen as about 0.7 , as is shown in Fig. 2. However, strictly speaking, we should choose a best fitted level $u$ in corresponding to this population correlation $\rho$ if we have any priori information about $\rho$.

Thirdly we can evaluate $E\left[C_{u}(X) \cdot C_{u}(Y)\right]$ which contains the terms $E[\operatorname{sgn}(X-u) \cdot \operatorname{sgn}(Y-u)], E[\operatorname{sgn}$ $(X-\mathrm{u}) \cdot \operatorname{sgn}(Y+u)], E[\operatorname{sgn}(X+u) \cdot \operatorname{sgn}(Y-u)]$, and $E[\operatorname{sgn}(X+u) \cdot \operatorname{sgn}(Y+u)]$. By the similar way to the evaluation of $E[X \cdot \operatorname{sgn}(X-u)]$ etc. (see Appendix (Theorem 3)), we can finally obtain the next for $-1<\rho<1$

$$
\begin{aligned}
& E\left[C_{u}(X) \cdot C_{u}(Y)\right]=\frac{1}{\pi} \int_{-\rho}^{\rho} \frac{1}{\sqrt{1-x^{2}}} \\
& \quad \times \exp \left(-\frac{u^{2}}{1+x}\right) d x
\end{aligned}
$$

and show that the equation (7) holds for the case $|\rho|=1$ with lengthy calculation. For the special case of $u=0.0$, we have

$$
E[\operatorname{sgn}(X) \cdot \operatorname{sgn}(Y)]=\frac{2}{\pi} \operatorname{Sin}^{-1} \rho .
$$

This known as a arcsin-law (e.g., M. Huzii (1974) p. 137).

\section{Series of index of climatic gross feature}

For the representation of gross feature over the several climatic time series, we take the total sum of clipped series tentatively (a use of mean can be better for some case),

$$
T_{p}(t)=\sum_{\alpha=1}^{p} C_{u}\left\{z_{\alpha}(t)\right\} \quad t=1, \cdots, N
$$

For the analysis of climatic time series we used the collected series ranging over A.D. 1200-1900 given by Kai (1979). Among them, we take 7 time series which are suitable to analyze;

(1) 10 years average of Wolf's sunspot numbers (Takahashi, 1975)

(2) Width of tree-rings in U.S.A. (Schove, 1978)

(3) Width of tree-rings in Germany (Schove, 1978)

(4) Concentration of ${ }^{14} \mathrm{C}$ in the atmosphere (Lerman, 1970)

(5) 20 years average of an index of good harvest estimated by difference of tree-rings from the one of the standard growth rate (Suda, 1951)

(6) Isotope ratio of oxygen in tree-rings of Yakushima, Japan (Pandolfi, et al., 1976)

(7) Isotope ratio of oxygen in tree-rings of Yakushima, Japan (Libby, et al., 1976)

These time series are reproduced in Fig. 3. The other time series had the very short period of observation or resulted in strong smoothing.

All values of time series read off each 5 years from the printed curves in the paper of Kai (1979) and $\left\{z_{\alpha}(t)\right\}$ (here $p=7, N=139$ ) are obtained after substraction of each value from its mean. Mean values and variances of original time series are given in Table 1. Series of indices $T_{p}(t)$ are computed for the three different crossing levels, i.e., $u=0,2 s / 3$ and $s$ where $s$ is the standard deviation. In the following analysis we use only the clipped series $C_{u}\left(z_{\alpha}(t)\right)$ for $u=2 s / 3 . T_{p}(t)$ series are given in Table 2 and shown in Fig. 4 only for $u=2 \mathrm{~s} / 3$. If the absolute value of $T_{p}(t)$ is equal to the total number of different time series, then there will be a complete concordance between them for each $t$. However we admit a weak concordance among $Z(t)$ for such a case when

$$
p \geqq\left|T_{p}(t)\right| \geqq p / 2 .
$$

By this criterion we can see that a warm period is in around A.D. 1570; a cold period is from A.D. 1680 to 1700 . The latter cold period cor- 


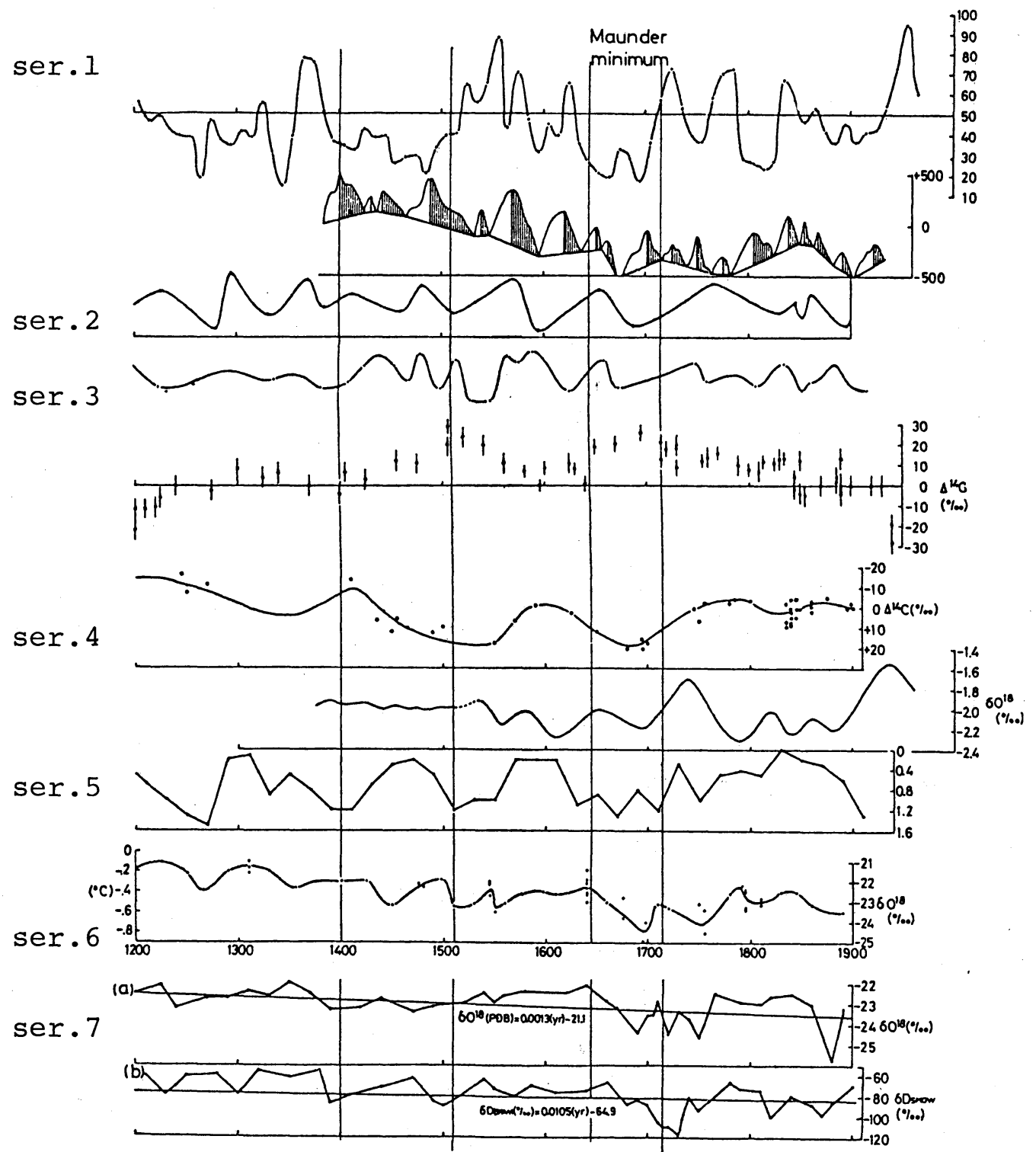

Fig. 3 Climatic time series 1.-7. (After K. Kai, 1979). 1. Sunspot numbers 10-yrs average (Takahashi, 1975), 2. Tree-ring width, USA (Schove, 1978), 3. Tree-ring width, Germany (Schove, 1978), 4. ${ }^{14} \mathrm{C}$ concentration (Lerman et al., 1970), 5. Index of good harvest (Suda, 1951), 6. Isotope ratio ${ }^{18} \mathrm{O} /{ }^{16} \mathrm{O}$, Yakushima tree-ring, Japan (Pandolfi et al.), 7. Isotope ratio ${ }^{18} \mathrm{O} /{ }^{16} \mathrm{O}$, Yakushima tree-ring, Japan (Libby et al., 1976).

responds to the Maunder minimum. In Fig. 4 the index series is compared with the change in time of eustasy and cosmic radiation (tree-ring ${ }^{14} \mathrm{C}$ ) given by Fairbridge (1961), and also sunspot numbers average for 10 years given by Takahashi (1979). There are reasonable match between cosmic radiation and eustasy. The index series is more similar to variation of cosmic radiation, although Fairbridge (1961) indicates a striking similarity between eustasy and sunspot curve smoothed to 100 -year means.

Now we consider a relation among autocovariance of $\left\{T_{p}(t)\right\}$, auto-covariance and crosscovariance of each hard limiting series as follows. Auto-covariances of $\left\{T_{p}(t)\right\}$ will be decomposed into two parts of auto-covariances and 
Table 1 Mean and variance of climatic series 1.-7. and index series $T_{p}(t)$.

\begin{tabular}{crr}
\hline Series & Mean & Variance \\
\hline 1 & 43.21 & 217.7202 \\
2 & 2.31 & 0.7794 \\
3 & 4.12 & 2.2598 \\
4 & 3.77 & 93.2422 \\
5 & 0.69 & 0.1425 \\
6 & -4.07 & 2.4580 \\
7 & 23.05 & 0.2900 \\
$T_{p}(t)$ & & \\
$u=0$ & -0.11 & 8.6575 \\
$u=2 s / 3$ & 0.07 & 5.7008 \\
$u=s$ & 0.17 & 3.7112 \\
\hline
\end{tabular}

Table 2 Climatic index series for the crossing levels (1) $u=0$, (2) $u=2 s / 3$, (3) $u=s$

\begin{tabular}{|c|c|c|c|c|c|c|c|c|c|c|c|}
\hline & (1) & (2) & (3) & & & (2) & (3) & & & (2) & (3) \\
\hline \multirow[t]{10}{*}{$1200 \mathrm{AD}$} & 5 & 4 & 2 & $1450 \mathrm{AD}$ & -3 & 0 & 1 & $1700 \mathrm{AD}$ & -7 & -5 & -4 \\
\hline & 7 & 2 & 2 & & -3 & 1 & 1 & & -3 & -4 & -1 \\
\hline & 5 & 3 & 2 & & -1 & 0 & 1 & & -5 & -3 & -1 \\
\hline & 3 & 3 & 3 & & -1 & 0 & 1 & & -5 & -1 & 0 \\
\hline & 3 & 2 & 2 & & 1 & 0 & 2 & & & -2 & -1 \\
\hline & 3 & 3 & 2 & & 1. & 1 & 1 & & 1 & 0 & -1 \\
\hline & 1 & 1 & 2 & & 1 & 2 & 1 & & & -1 & -1 \\
\hline & $-1-$ & -1 & 0 & & 1 & 1 & 0 & & & -2 & -2 \\
\hline & -1 & 0 & 0 & & 1 & 1 & -1 & & -3 & 0 & -2 \\
\hline & -1 & -1 & 0 & & -1 & 0 & -1 & & -1 & 0 & 0 \\
\hline \multirow[t]{10}{*}{1250} & -3 & 0. & -1 & 1500 & -3 & -3 & -1 & 1750 & -1 & 0 & 0 \\
\hline & $-3-$ & -3 & -1 & & -5 & -5 & -3 & & -1 & 1 & 1 \\
\hline & -3 & -3 & -2 & & -5 & -4 & -1 & & 3 & 1 & 1 \\
\hline & $-3-$ & -2 & -2 & & -1 & 0 & -1 & & 3 & 3 & 3 \\
\hline & -1 & -1 & -1 & & -1 & -1 & 0 & & 3 & 4 & 2 \\
\hline & -1 & 1 & 0 & & -4 & 0 & 0 & & 3 & 3 & 2 \\
\hline & 3 & 2 & 0 & & -1 & 0 & -2 & & 3 & 4 & 2 \\
\hline & 3 & 4 & 1 & & 1 & 0 & -1 & & 3 & 3 & 0 \\
\hline & 3 & 3 & 3 & & 1 & -1 & -2 & & 1 & 0 & 0 \\
\hline & 3 & 3 & 3 & & -1 & -1 & -1 & & & -1 & 0 \\
\hline \multirow[t]{10}{*}{1300} & 3 & 3 & 3 & 1550 & -1 & -1 & 0 & 1800 & -1 & -1 & -1 \\
\hline & 5 & 3 & 3 & & 1 & 2 & 1 & & -3 & -2 & -1 \\
\hline & 3 & 2 & 2 & & 1 & 2 & 3 & & -1 & -1 & -1 \\
\hline & 1 & 1 & 1 & & 3 & 5 & 5 & & -3 & -1 & 0 \\
\hline & -3 & 2 & 1 & & 3 & 5 & 5 & & -3 & 0 & 0 \\
\hline & -1 & 0 & 1 & & 7 & 5 & 4 & & 3 & 2 & 3 \\
\hline & -3 & -1 & -1 & & 5 & 3 & 3 & & 3 & 2 & 3 \\
\hline & $-3-$ & -1 & -1 & & 3 & 2 & 2 & & 3 & 3 & 2 \\
\hline & -1 & -1 & -1 & & 3 & 1 & 2 & & 5 & 2 & 1 \\
\hline & -1 & 0 & 1 & & 3 & 2 & 2 & & 1 & 1 & 1 \\
\hline \multirow[t]{10}{*}{1350} & -1 & 0 & 0 & 1600 & 3 & 2 & 2 & 1850 & & -1 & 1 \\
\hline & 1 & 2 & 1 & & 3 & 2 & 2 & & 1 & 0 & 0 \\
\hline & 1 & 2 & 2 & & 3 & 1 & 0 & & & -2 & -1 \\
\hline & 1 & 3 & 2 & & 2 & 0 & 1 & & & -2 & 0 \\
\hline & 1 & 2 & 2 & & -1 & 1 & 2 & & & -1 & -1 \\
\hline & 1 & 1 & 0 & & -1 & -1 & -1 & & & -2 & -2 \\
\hline & $-1-$ & -2 & -2 & & -1 & -1 & 0 & & & -3 & -2 \\
\hline & -3 & -1 & -2 & & -1 & -1 & 1 & & & -1 & -2 \\
\hline & -3 & 0 & -1 & & -1 & 0 & 1 & 1890 & -1 & -2 & -2 \\
\hline & -3 & 0 & -1 & & -1 & 0 & 1 & & & & \\
\hline \multirow[t]{9}{*}{1400} & -1 & 0 & 0 & 1650 & -1 & 0 & 0 & & & & \\
\hline & -1 & 0 & 0 & & -1 & -2 & -2 & & & & \\
\hline & -1 & 1 & 0 & & -1 & -3 & -2 & & & & \\
\hline & -1 & 1 & 1 & & -5 & -3 & -2 & & & & \\
\hline & 1 & 2 & 0 & & -5 & -5 & -3 & & & & \\
\hline & 5 & 1 & 0 & & -7 & -7 & -6 & & & & \\
\hline & 1 & 0 & 1 & & -7 & -6 & -5 & & & & \\
\hline & 1 & 1 & 1 & & -7 & -6 & -5 & & & & \\
\hline & -1 & 2 & 2 & & -7 & -6 & -5 & & & & \\
\hline 1445 & -1 & 0 & 2 & 1695 & -7 & -7 & -4 & & & & \\
\hline
\end{tabular}

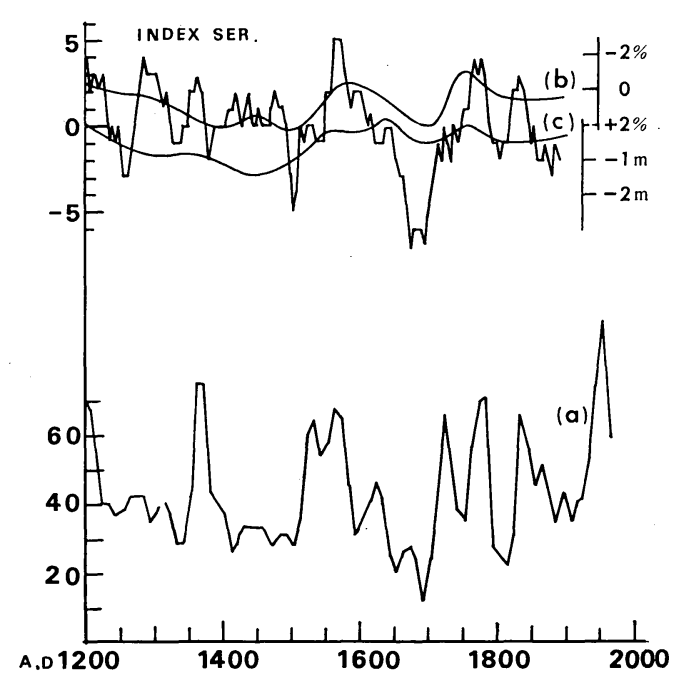

Fig. 4 Index series $\left[T_{p}(t) ; \mathrm{t}=1,2, \ldots, 139\right]$ from A.D. 1200 to 1900 ) for the crossing level $u=2 s / 3$, (a) ser. 1 (10-yrs average sunspot numbers, Takahashi, 1979), (b) cosmic radiation (tree-ring ${ }^{14} \mathrm{C}$, Fairbridge, 1961) and (c) Eustasy (Fairbridge, 1961).

cross-covariances in clipped series set $\left\{C_{u}\left(z_{\alpha}(t)\right)\right\}$;

$$
\begin{aligned}
E & {\left[T_{p}(t) T_{p}(t+h)\right] } \\
& \left.=E\left[\sum_{\alpha=1}^{p} C_{u}\left\{z_{\alpha}(t)\right\} \sum_{\alpha=1}^{p} C_{u}\{t+h)\right\}\right] \\
& =\sum_{\alpha=1}^{p} E\left[C_{u}\left\{z_{\alpha}(t)\right\} C_{u}\left\{z_{\alpha}(t+h)\right\}\right] \\
& +\sum_{\alpha \neq \beta} E\left[C_{u}\left\{z_{\alpha}(t)\right\} C_{u}\left\{z_{\beta}(t+h)\right\}\right] .
\end{aligned}
$$

If we assume that a pair of $z_{\alpha}(t)$ and $z_{\alpha}(t+h)$ follows to a bi-variate normal distribution $N(0$, $\left.0,1,1 ; \rho_{\alpha \alpha}\right)$, and $z_{\alpha}(t)$ and $z_{\beta}(t)$ follows $N(0,0$, 1,$\left.1 ; \rho_{\alpha \beta}\right)$, then we have the next expression for the fixed $t$ and $t+h$

$$
E\left[C_{u}\left\{z_{\alpha}(t)\right\} C_{u}\left\{z_{\alpha}(t+h)\right\}\right]=\Psi\left\{\rho_{\alpha \alpha}(h)\right\}
$$

and

$$
E\left[C_{u}\left\{z_{\alpha}(t)\right\} C_{u}\left\{z_{\beta}(t+h)\right\}\right]=\Psi\left\{\rho_{\alpha \beta}(h)\right\}
$$

where in general

$$
\Psi_{i j}(h)=\frac{1}{\pi} \int_{-\rho}^{\rho} \frac{1}{\sqrt{1-x^{2}}} \exp \left(-\frac{u^{2}}{1+x}\right) d x
$$

for $i, j=\alpha, \beta$.

Therefore we have

$$
E\left[T_{p}(t) T_{p}(t+h)\right]=\sum_{\alpha} \Psi\left\{\rho_{\alpha \alpha}(h)\right\}+\sum_{\alpha \neq \beta} \Psi\left\{\rho_{\alpha \beta}(h)\right\} .
$$

An sample estimator of $E\left[T_{p}(t) T_{p}(t+h)\right]$ is 


$$
\gamma_{T}(h ; u=2 s / 3)=\frac{1}{N} \sum_{t=1}^{N-h} T_{p}(t) T_{p}(t+h) .
$$

Auto-covariance $E\left[C_{u}\left(z_{\alpha}(t) C_{u}\left(z_{\alpha}(t+h)\right)\right]\right.$ and cross-covariance $E\left[C_{u}\left(z_{\alpha}(t)\right) C_{u}\left(z_{\beta}(t+h)\right)\right]$ of hard limiting series are estimated by

$$
\gamma_{c}(h ; \alpha)=\frac{1}{N} \sum_{t=1}^{N-h} C_{u}\left\{z_{\alpha}(t)\right\} C_{u}\left\{z_{\alpha}(t+h)\right\}
$$

and

$$
\gamma_{c}(h ; \alpha, \beta)=\frac{1}{N} \sum_{t=1}^{N-h} C_{u}\left\{z_{\alpha}(t)\right\} C_{u}\left\{z_{\beta}(t+h)\right\}
$$

respectively. From the definition of $T_{p}(t)$ we have a similar relation

$$
\gamma_{T}(h ; u)=\gamma_{C}(h ; \alpha)+\gamma_{C}(h ; \alpha, \beta)
$$

for these estimators. To see estimation error of $\gamma_{\mathrm{c}}(h ; \alpha), E\left[C_{u}\left(z_{\alpha}(t)\right) C_{u}\left(z_{\alpha}(t+h)\right)\right]$ are plotted for $\tilde{\rho}$ in Fig. 5 , where $\tilde{\rho}$ is estimated by an ordinary estimator as

$$
\tilde{\rho}=\frac{1}{N} \sum_{t=1}^{N-h} z_{\alpha}(t) z_{\alpha}(t+h)
$$

and the following estimator $\tilde{\rho}(h ; u)$, i.e.,

$$
\begin{aligned}
& \tilde{\rho}(h ; u)=N / 2(N-h) \\
& \times \frac{\sum_{t=1}^{N-h}\left[z_{\alpha}(t) C_{u}\left\{z_{\alpha}(t+h)\right\}+z_{\alpha}(t+h) C_{u}\left\{z_{\alpha}(t)\right\}\right]}{\sum_{t=1}^{N} z_{\alpha}(t) C_{u}\left\{z_{\alpha}(t)\right\}}
\end{aligned}
$$

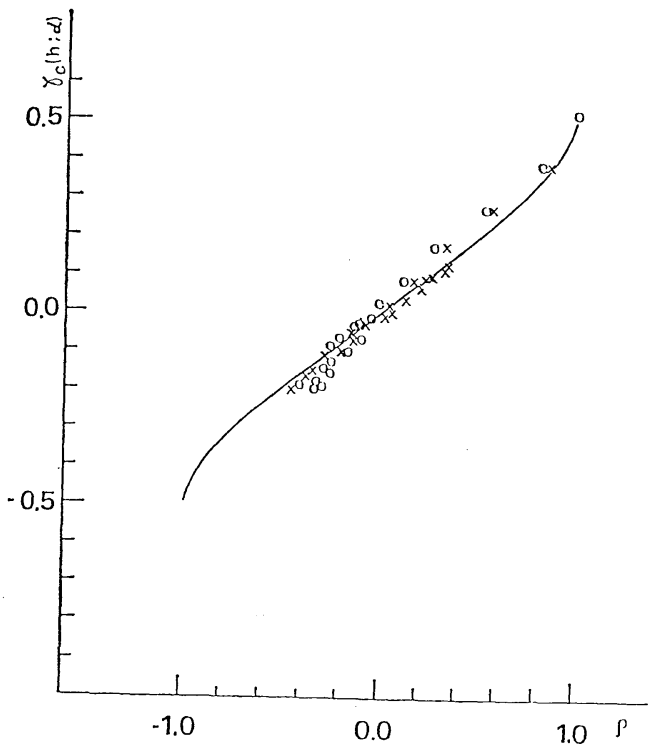

Fig. 5 Estimated autocorrelation of hard limiting series $\gamma_{c}(h ; \alpha)$ and the theoretical integral $\Psi\left(\rho_{\alpha \alpha}\right)$ with estimated autocorrelations $(\tilde{\rho}(h ; u)$; cross, and $\tilde{\rho}$; circles) for ser. 1.
The latter estimator is not unbiased and is reduced to the Huzii's estimator (1963) for the case $u=0.0$, since $z_{\alpha}(t) C_{u}\left(z_{\alpha}(t+h)\right)=\left|z_{\alpha}(t)\right|$ is satisfied. When we use the above estimator $\tilde{\rho}$ $(h ; u), \gamma_{c}(h ; \alpha)$ is rather near to $\Psi\left(\rho_{\alpha \alpha}\right)$ given by the equation (9) with a small difference as shown in Fig. 5. These differences for other hard limiting series are evaluated as $\gamma_{c}(h ; \alpha)-\Psi(\tilde{\rho}(h ; u))$ at each lag $h$. Difference values extend over about -0.06 to 0.07 . Mean values and variances of them are given at each lag in Table 3. This table

Table 3 Means and variances of the difference of estimator of $E\left[\operatorname{sgn} Z_{\alpha}(t) \operatorname{sgn} Z_{\alpha}(t+h)\right]$ from $\Psi\{\tilde{\rho}(h ; \alpha)\}$ at each lag.

\begin{tabular}{crc}
\hline lag h & mean & variance \\
\hline 0 & $0.68259 \mathrm{D}-02$ & $0.34076 \mathrm{D}-02$ \\
1 & $0.16018 \mathrm{D}-01$ & $0.20743 \mathrm{D}-02$ \\
2 & $0.17078 \mathrm{D}-01$ & $0.12295 \mathrm{D}-02$ \\
3 & $0.14392 \mathrm{D}-01$ & $0.41188 \mathrm{D}-03$ \\
4 & $0.12160 \mathrm{D}-01$ & $0.22443 \mathrm{D}-03$ \\
5 & $0.11773 \mathrm{D}-01$ & $0.14583 \mathrm{D}-03$ \\
6 & $0.65249 \mathrm{D}-02$ & $0.13760 \mathrm{D}-03$ \\
7 & $0.10301 \mathrm{D}-01$ & $0.30966 \mathrm{D}-04$ \\
8 & $0.11805 \mathrm{D}-01$ & $0.94738 \mathrm{D}-04$ \\
9 & $0.65898 \mathrm{D}-02$ & $0.25558 \mathrm{D}-03$ \\
10 & $0.34662 \mathrm{D}-02$ & $0.36807 \mathrm{D}-03$ \\
11 & $0.22644 \mathrm{D}-02$ & $0.32392 \mathrm{D}-03$ \\
12 & $-0.18568 \mathrm{D}-02$ & $0.25259 \mathrm{D}-03$ \\
13 & $-0.65724 \mathrm{D}-02$ & $0.19348 \mathrm{D}-03$ \\
14 & $-0.42683 \mathrm{D}-02$ & $0.52901 \mathrm{D}-04$ \\
15 & $-0.32126 \mathrm{D}-02$ & $0.15723 \mathrm{D}-03$ \\
16 & $0.20249 \mathrm{D}-02$ & $0.21782 \mathrm{D}-03$ \\
17 & $0.63569 \mathrm{D}-02$ & $0.19598 \mathrm{D}-03$ \\
18 & $0.95188 \mathrm{D}-02$ & $0.18266 \mathrm{D}-03$ \\
19 & $0.94321 \mathrm{D}-02$ & $0.28673 \mathrm{D}-03$ \\
20 & $0.60716 \mathrm{D}-02$ & $0.37522 \mathrm{D}-03$ \\
21 & $0.12676 \mathrm{D}-01$ & $0.45530 \mathrm{D}-03$ \\
22 & $0.97309 \mathrm{D}-02$ & $0.16631 \mathrm{D}-03$ \\
23 & $0.14646 \mathrm{D}-01$ & $0.22431 \mathrm{D}-03$ \\
24 & $0.10755 \mathrm{D}-01$ & $0.13913 \mathrm{D}-03$ \\
25 & $0.52215 \mathrm{D}-02$ & $0.20697 \mathrm{D}-03$ \\
26 & $0.11062 \mathrm{D}-02$ & $0.18274 \mathrm{D}-03$ \\
27 & $-0.93620 \mathrm{D}-03$ & $0.30349 \mathrm{D}-03$ \\
28 & $-0.20455 \mathrm{D}-02$ & $0.44895 \mathrm{D}-03$ \\
29 & $-0.85216 \mathrm{D}-02$ & $0.29881 \mathrm{D}-03$ \\
30 & $-0.12009 \mathrm{D}-01$ & $0.45660 \mathrm{D}-03$ \\
31 & $-0.10428 \mathrm{D}-01$ & $0.58768 \mathrm{D}-03$ \\
32 & $-0.47370 \mathrm{D}-02$ & $0.60736 \mathrm{D}-03$ \\
33 & $-0.54464 \mathrm{D}-02$ & $0.42953 \mathrm{D}-03$ \\
34 & $-0.60404 \mathrm{D}-02$ & $0.15643 \mathrm{D}-03$ \\
35 & $-0.95849 \mathrm{D}-02$ & $0.19923 \mathrm{D}-03$ \\
36 & $-0.10690 \mathrm{D}-01$ & $0.26966 \mathrm{D}-03$ \\
38 & $-0.13779 \mathrm{D}-01$ & $0.47008 \mathrm{D}-03$ \\
& $-0.13913 \mathrm{D}-01$ & $0.80924 \mathrm{D}-03$ \\
& $-0.79168 \mathrm{D}-02$ & $0.12710 \mathrm{D}-02$ \\
\hline 0 & $-0.18728 \mathrm{D}-02$ & $0.10972 \mathrm{D}-02$ \\
\hline & & \\
\hline 3 & &
\end{tabular}


suggests that $\Psi(\tilde{\rho}(h ; \alpha))$ becomes a good approximation to $\gamma_{c}(h ; \alpha)$ at each lag $h$.

\section{Conclusion}

Here we proposed an index showing gross feature of climatic time series as the total of each hard limiting series and a weak concordance given by a certain criterion will be interpreted by the climatological cold periods. The variation in time of this index reflects variations extending from solar activity to eustasy and depends on the characteristics of original climatic time series. These evidences probably allow for the index to be a synthetic climatological measure and to proceed in further statistical analysis of the index series. Before constructing the time series model such as ARMA (autoregressive moving average) for the series of index for the purpose of prediction, it is necessary to study the statistical properties of the index series itself.

Under the condition that a pair of sample follows to a bi-variate normal distribution with known mean and variance, an unbiased estimator of population correlation is given from the original series and its hard limiting series obtained by the use of the crossing level $u$.

An optimum level $u$ for the estimation of autocorrelation is given as about $2 / 3$ of the standard deviation by the criterion of minimum variance of estimator for the case of unknown true autocorrelation.

Cross-covariance of the index series are decomposed into two parts; the one is the sum of auto-covariance of hard limiting series and the other is the sum of cross-covariance of them. Both auto-covariance and cross-covariance of each hard limiting series are written by a function of population correlation.

\section{Acknowledgements}

Author's thanks to Prof. M. M. Yoshino, Tsu- kuba University and to Prof. S. Ikeda, Soka University for the encouragement to this study. Thanks are also due to the refree for his useful comments on the paper.

\section{Appendix}

In the following discussion, we adopt a hard limiting procedure with the two upper and lower different levels $u$ and $v$ as follows:

$$
C_{u, v}(X)=\left\{\begin{array}{rc}
+1 & X>u \\
0 & -v \leqq x \leqq u \\
-1 & X<-v
\end{array}\right.
$$

where $u$ and $v$ are arbitrary non-negative real numbers.

We can use the next notation for simplicity

$$
\begin{aligned}
& C_{u}(X)=C_{u, u}(X), \operatorname{sgn}(X)=C_{0}(X)=C_{0,0}(X), \\
& C_{u, v}(X)=\frac{1}{2}[\operatorname{sgn}(X-u)+\operatorname{sgn}(X+v)] .(\mathrm{A} 1)
\end{aligned}
$$

Let us put the following two assumptions; [Assumption I] $\{X(t)\}, t=\cdots,-2,-1,0,1$, $2, \cdots$ is a real stationary stochastic process with mean $E[X(t)]=\mu$, and auto-covariance $\operatorname{cov}[X(t)$, $X(t+h)]=\sigma^{2} \rho(h)$. If both $\mu$ and $\sigma^{2}$ are known, then we can put $\mu=0, \sigma^{2}=1$ without the loss of generality.

[Assumption II] Denoting $X \equiv X(t), \quad Y \equiv X(t+h)$, a pair of random variable $(X, Y)$ follows to a bi-variate normal distribution $N(0,0,1,1 ; \rho)$ for each interval $h$.

Evaluation of $E[X \cdot \operatorname{sgn}(Y-u)]$ and unbiased estimator $\tilde{\rho}$; we calculate $\mathrm{E}[\mathrm{X} \cdot \operatorname{sgn}(\mathrm{Y}-\mathrm{u})]$, under noticing that

$$
\operatorname{sgn}(x)=\frac{1}{\pi i} \lim _{\varepsilon \downarrow 0} \lim _{L \rightarrow \infty} \int_{L \geq|t| \geq \varepsilon} \frac{1}{t} \exp (i t x) d t
$$

and with abbreviated notation

$$
\operatorname{sgn}(x)=\frac{1}{\pi i} \text { p.v. } \int_{-\infty}^{\infty} \frac{1}{t} \exp (i t x) d t
$$

where $P . V$. means principal value, and the above integral is bounded. Now we have

$$
\begin{aligned}
& E[X \cdot \operatorname{sgn}(Y-u)]=\frac{1}{\pi i} E\left[X \cdot \text { p.v. } \int_{-\infty}^{\infty} \exp \{i(Y-u) t\} d t / t\right. \\
& =\frac{1}{\pi i} \int_{-\infty}^{\infty} \int_{-\infty}^{\infty}\left[\text { p.v. } \int_{-\infty}^{\infty} \exp \{i(y-u) t\} d t / t\right] x \cdot f_{2}(x, y) d x d y
\end{aligned}
$$

where $f_{2}(x, y)$ is a joint probablity density function of bi-variate normal distribution, and the possible domains of $x$ and $y$ are given by

$$
E_{1}=\{-\infty<x<\infty, u \leqq y<\infty\}, \quad E_{2}=\{-\infty<x<\infty,-\infty<y<u\} .
$$

By the dominated convergence theorem we have

$$
\lim _{\varepsilon \downarrow 0} \lim _{L \rightarrow \infty} \iint_{E j} h_{\varepsilon}, L(y) d \mu(x, y)=\iint_{E j} x \cdot \operatorname{sgn}(y-u) \cdot f_{2}(x, y) d x d y
$$


where $j=1,2$ and

$$
h_{\varepsilon}, L(y)=\int_{L \geq|t| \geq \varepsilon} \exp \{i(y-u) t\} d t / t .
$$

This shows that the symbol exchange between p.v. $\int$ and $E$ is possible, so we have

$$
\begin{aligned}
E[X \cdot \operatorname{sgn}(Y-u)] & =\frac{1}{\pi i} \text { p.v. } \int_{-\infty}^{\infty}[E[X \cdot \exp \{-i(Y-u) t\}] / t] d t \\
& =\frac{\rho}{\pi} \text { p.v. } \int_{-\infty}^{\infty} \exp \left(-\frac{t^{2}}{2}-i u t\right) d t=\sqrt{\frac{2}{\pi}} \rho \exp \left(-\frac{u^{2}}{2}\right)
\end{aligned}
$$

because of

$$
E[X \cdot \exp (i Y t)]=-\left.i \frac{d}{d v} E[\exp (i Y t+i X v)]\right|_{v=0}=-\left.i \frac{d}{d v} \exp \left\{-\left(t^{2}+2 \rho t v+v^{2}\right) / 2\right\}\right|_{v=0}=i \rho t \exp \left(-t^{2} / 2\right) .
$$

We have

$$
E\left[X \cdot C_{u}, v(Y)\right]=\frac{1}{2} \sqrt{\frac{2}{\pi}} \rho\left\{\exp \left(-\frac{u^{2}}{2}\right)+\exp \left(-\frac{v^{2}}{2}\right)\right\} .
$$

After all, we have

$$
E\left[X \cdot C_{u}, v(Y)+Y \cdot C_{u}, v(X)\right]=\sqrt{\frac{2}{\pi}} \rho\left\{\exp \left(-\frac{u^{2}}{2}\right)+\exp \left(-\frac{v^{2}}{2}\right)\right\} .
$$

Hence we have the following lemma 1 .

(Lemma 1) When a pair of random variable $(X, Y)$ follows $N(0,0,1,1 ; \rho)$, we have

$$
\tilde{\rho}=\sqrt{\frac{\pi}{2}}\left\{\exp \left(-\frac{u^{2}}{2}\right)+\exp \left(-\frac{v^{2}}{2}\right)\right\}^{-1}\left[X \cdot C_{u}, v(Y)+Y \cdot C_{u, v}(X)\right]
$$

and $\tilde{\rho}$ is an unbiased estimator of $\rho$. For the particular case of $u=v$, we have

$$
\tilde{\rho}=\frac{\sqrt{2 \pi}}{4} \exp \left(\frac{u^{2}}{2}\right) \cdot\left[X \cdot C_{u}(Y)+Y \cdot C_{u}(X)\right]
$$

and also, we have

$$
\tilde{\rho}=\frac{\sqrt{2 \pi}}{4}[X \cdot \operatorname{sgn}(Y)+Y \cdot \operatorname{sgn}(X)]
$$

for the special case of $u=v=0$.

Evaluation of var $(\tilde{\rho})$; By using the next two relations

$$
\begin{aligned}
& \tilde{\rho}^{2}=\frac{\pi}{2}\left\{\exp \left(-\frac{u^{2}}{2}\right)+\exp \left(-\frac{v^{2}}{2}\right)\right\}^{-2} \cdot\left\{X^{2} \cdot C^{2} u, v(Y)+Y^{2} \cdot C^{2} u, v(X)+2 X Y C_{u, v}(X) C_{u, v}(Y)\right\}, \\
& 4 X Y C_{u, v}(X) C_{u, v}(Y)=X Y\{\operatorname{sgn}(X-u) \operatorname{sgn}(Y-u)+\operatorname{sgn}(X-u) \operatorname{sgn}(Y+v) \\
& \quad+\operatorname{sgn}(X+v) \operatorname{sgn}(Y-u)+\operatorname{sgn}(X+v) \operatorname{sgn}(Y+v)\},
\end{aligned}
$$

we have

$$
\begin{aligned}
E\left[\tilde{\rho}^{2}\right] & =\frac{\pi}{4}\left\{\exp \left(-\frac{u^{2}}{2}\right)+\exp \left(-\frac{v^{2}}{2}\right)\right\}^{-2}\left\{2 E\left[X^{2} C^{2} u, v(Y)\right]+2 E\left[Y^{2} C^{2} u, v(X)\right]\right. \\
& +E[X Y \operatorname{sgn}(X-u) \operatorname{sgn}(Y-u)]+E[X Y \operatorname{sgn}(X-u) \operatorname{sgn}(Y+v)] \\
& +E[X Y \operatorname{sgn}(X+v) \operatorname{sgn}(Y-u)]+E[X Y \operatorname{sgn}(X+v) \operatorname{sgn}(Y+v)]\} .
\end{aligned}
$$

Each term of the above equation (A7) can be evaluated in the following way. Firstly, we evaluate

$$
E\left[X^{2} C^{2} u, v(Y)\right]=\int_{x=-\infty}^{\infty} \int_{y=u}^{\infty} x^{2} f_{2}(x, y) d x d y+\int_{x=-\infty}^{\infty} \int_{y=-\infty}^{-v} x^{2} f_{2}(x, y) d x d y=I(\rho, u)+I(-\rho, v)
$$

where 


$$
\begin{aligned}
I(\rho, u) & =\int_{y=u}^{\infty} \frac{1}{2 \pi \sqrt{1-\rho^{2}}} \exp \left(-\frac{y^{2}}{2\left(1-\rho^{2}\right)}\right)\left[\int_{-\infty}^{\infty} x^{2} \exp \left(-\frac{1}{2\left(1-\rho^{2}\right)} x^{2}+2 \frac{\rho y}{2\left(1-\rho^{2}\right)} x\right) d x\right] d y \\
& =\frac{1}{\sqrt{2 \pi}} \int_{u}^{\infty} \exp \left(-\frac{y^{2}}{2}\right) d y+\frac{\rho^{2}}{\sqrt{2 \pi}} u \exp \left(-\frac{u^{2}}{2}\right)
\end{aligned}
$$

and $I(-\rho, v)$ is written by the same way. Then we have

$$
\begin{gathered}
E\left[X^{2} C^{2} u, v(Y)\right]=\int_{u}^{\infty} \frac{1}{\sqrt{2 \pi}} \exp \left(-\frac{y^{2}}{2}\right) d y+\int_{v}^{\infty} \frac{1}{\sqrt{2 \pi}} \exp \left(-\frac{y^{2}}{2}\right) d y \\
+\frac{\rho^{2}}{\sqrt{2 \pi}} v \exp \left(-\frac{v^{2}}{2}\right)+\frac{1}{\sqrt{2 \pi}} u \exp \left(-\frac{u^{2}}{2}\right) .
\end{gathered}
$$

From the next symmetry of $X$ and $Y$,

$$
E\left[Y^{2} C^{2} u, v(X)\right]=2 E\left[X^{2} C^{2} u, v(Y)\right]
$$

we have the first two terms of the equation (A7) as follows,

$$
\begin{gathered}
2 E\left[X^{2} C^{2} u, v(Y)\right]+2 E\left[Y^{2} C^{2} u, v(X)\right]=4\left\{\int_{u}^{\infty} \frac{1}{\sqrt{2 \pi}} \exp \left(-\frac{y^{2}}{2}\right) d y+\int_{v}^{\infty} \frac{1}{\sqrt{2 \pi}} \exp \left(-\frac{y^{2}}{2}\right) d y\right. \\
\left.+\frac{\rho^{2}}{\sqrt{2 \pi}} u \exp \left(-\frac{u^{2}}{2}\right)+\frac{\rho^{2}}{\sqrt{2 \pi}} v \exp \left(-\frac{v^{2}}{2}\right)\right\} .
\end{gathered}
$$

Secondly, we evaluate the term $E[X Y \cdot \operatorname{sgn}(Y-u) \operatorname{sgn}(X-v)]$. The exchange between p.v. $\int$ and $E$ is possible in a similar way as in Lemma 1 . Since

$$
\begin{aligned}
& E[X Y \exp (i Y t+i X s)]=-\frac{\partial^{2}}{\partial t \partial s} E[\exp (i Y t+i X s)]=\left\{\rho-\left(1+\rho^{2}\right) s t-\rho\left(s^{2}+t^{2}\right)\right\} \\
& \quad \times \exp \left\{-\left(s^{2}+2 \rho s t+t^{2}\right) / 2\right\}
\end{aligned}
$$

we have

$$
\begin{aligned}
& E[X Y \operatorname{sgn}(Y-u) \operatorname{sgn}(X-v)] \\
& \quad=E\left[X Y \frac{1}{\pi i} \text { p.v. } \int \exp \{i(Y-u) t\} d t / t \frac{1}{\pi i} \text { p.v. } \int \exp \{i(X-v) s\} d s / s\right] \\
& \quad=\frac{1}{\pi^{2}} \text { p.v. } \int \text { p.v. } \int\left\{\rho\left(s^{2}+t^{2}\right)+\left(1+\rho^{2}\right) s t-\rho\right\} \exp \left\{-\left(s^{2}+2 \rho s t+t^{2}+2 i u t+2 i v s\right) / 2\right\}(d t / t)(d s / s) \\
& =\frac{\rho}{\pi^{2}} I_{1}+\frac{\rho}{\pi^{2}} I_{2}+\frac{1+\rho^{2}}{\pi^{2}} I_{3}-\frac{\rho}{\pi^{2}} I_{4}
\end{aligned}
$$

where

$$
\begin{aligned}
& I_{1}=\text { p.v. } \int \text { p.v. } \int \frac{s}{t} \exp \left[-\left(s^{2}+2 \rho s t+t^{2}+2 i u t+2 i v s\right) / 2\right] d t d s, \\
& I_{2}=\text { p.v. } \int \text { p.v. } \int \frac{t}{s} \exp \left[-\left(s^{2}+2 \rho s t+t^{2}+2 i u t+2 i v s\right) / 2\right] d t d s, \\
& I_{3}=\text { p.v. } \int \text { p.v. } \int \exp \left[-\left(s^{2}+2 \rho s t+t^{2}+2 i u t+2 i v s\right) / 2\right] d t d s, \\
& I_{4}=\text { p.v. } \int \text { p.v. } \int \frac{1}{t s} \exp \left[-\left(s^{2}+2 \rho s t+t^{2}+2 i u t+2 i v s\right) / 2\right] d t d s
\end{aligned}
$$

Thus we now evaluate each integral $I_{i}, i=1,2,3,4$.

Evaluation of $I_{1}$ and $I_{2} ; I_{1}$ and $I_{2}$ are mutually interchangeable with $u$ and $v$, so it is enough to evaluate $I_{1}$ only. By using

$$
\int_{-\infty}^{\infty} s^{2} \exp \left[-\frac{s^{2}}{2}-(\rho t+i v) s\right] d s=\sqrt{2 \pi}\left(1-v^{2}+2 i \rho v t+\rho^{2} t^{2}\right) \exp \left[-\frac{1}{2}\left(v^{2}-2 i v \rho t-\rho^{2} t^{2}\right)\right],
$$

we obtain 


$$
\begin{aligned}
\frac{\partial I_{1}}{\partial \rho} & =- \text { p.v. } \int \text { p.v. } \int s^{2} \exp \left[-\frac{1}{2}\left(s^{2}+2 \rho s t+t^{2}+2 i u t+2 i v s\right)\right] d t d s \\
& =-\int_{-\infty}^{\infty} \int_{-\infty}^{\infty} s^{2} \exp \left[-\frac{1}{2}\left(s^{2}+2 \rho s t+t^{2}+2 i u t+2 i v s\right)\right] d t d s \\
& =-\sqrt{2 \pi}\left(1-v^{2}\right) \exp \left(-\frac{v^{2}}{2}\right) \cdot J_{1}-\sqrt{2 \pi} 2 i \rho v \exp \left(-\frac{v^{2}}{2}\right) \cdot J_{2}-\sqrt{2 \pi} \rho^{2} \exp \left(-\frac{v^{2}}{2}\right) \cdot J_{3}
\end{aligned}
$$

where

$$
\begin{aligned}
& J_{1}=\int_{-\infty}^{\infty} \exp \left[--\frac{1}{2}\left(1-\rho^{2}\right) t^{2}-i(u-\rho v) t\right] d t=\frac{\sqrt{2 \pi}}{\sqrt{1-\rho^{2}}} \exp \left[-\frac{(u-\rho v)^{2}}{2\left(1-\rho^{2}\right)}\right], \\
& J_{2}=\int_{-\infty}^{\infty} t \exp \left[-\frac{1}{2}\left(1-\rho^{2}\right) t^{2}-i(u-\rho v) t\right] d t=i \frac{\sqrt{2 \pi}}{\left(1-\rho^{2}\right)^{3 / 2}}(u-\rho v) \exp \left[-\frac{(u-\rho v)^{2}}{2\left(1-\rho_{2}\right)}\right], \\
& J_{3}=\int_{-\infty}^{\infty} t^{2} \exp \left[-\frac{1}{2}\left(1-\rho^{2}\right) t^{2}-i(u-\rho v) t\right] d t=\frac{\sqrt{2 \pi}}{\left(1-\rho^{2}\right)^{3 / 2}}\left(1-\frac{(u-\rho v)^{2}}{1-\rho^{2}}\right) \exp \left[-\frac{(u-\rho v)^{2}}{2\left(1-\rho^{2}\right)}\right] .
\end{aligned}
$$

Thus we have

$$
\begin{aligned}
\frac{\partial I_{1}}{\partial \rho} & =-\frac{2 \pi}{\sqrt{1-\rho^{2}}}\left(1-v^{2}\right) \exp \left[-\frac{u^{2}-2 \rho u v+v^{2}}{2\left(1-\rho^{2}\right)}\right]+\frac{4 \pi}{\left(1-\rho^{2}\right)^{3 / 2}} \rho v(u-\rho v) \exp \left[-\frac{u^{2}-2 \rho u v+v^{2}}{2\left(1-\rho^{2}\right)}\right] \\
& -\frac{2 \pi}{\left(1-\rho^{2}\right)^{3 / 2}} \rho^{2}\left(1-\frac{(u-\rho v)^{2}}{1-\rho^{2}}\right) \exp \left[-\frac{u^{2}-2 \rho u v+v^{2}}{2\left(1-\rho^{2}\right)}\right] .
\end{aligned}
$$

On the other hand, under noticing that

$$
\left.I_{1}\right|_{\rho=0}=-2 \pi v \exp \left(-\frac{1}{2} v^{2}\right) \int_{0}^{u} \exp \left(-\frac{1}{2} x^{2}\right) d x,
$$

we have

$$
\begin{aligned}
I_{1}= & -2 \pi v \exp \left(-\frac{1}{2} v^{2}\right) \int_{0}^{u} \exp \left(-\frac{1}{2} x^{2}\right) d x-2 \pi\left(1-v^{2}\right) \int_{0}^{\rho} \frac{1}{\sqrt{1-x^{2}}} \exp \left[-\frac{u^{2}-2 u v x+v^{2}}{2\left(1-x^{2}\right)}\right] d x \\
& +4 \pi v \int_{0}^{\rho} \frac{x(u-v x)}{\left(1-x^{2}\right)^{3 / 2}} \exp \left[-\frac{u^{2}-2 u v x+v^{2}}{2\left(1-x^{2}\right)}\right] d x \\
& -2 \pi \int_{0}^{\rho} \frac{x^{2}}{\left(1-x^{2}\right)^{3 / 2}}\left(1-\frac{(u-v x)^{2}}{1-x^{2}}\right) \exp \left[-\frac{u^{2}-2 u v x+v^{2}}{2\left(1-x^{2}\right)}\right] d x .
\end{aligned}
$$

Evaluation of $I_{3}$; we have the next result of an ordinary Riemann integral

$$
I_{3}=\int_{-\infty}^{\infty} \int_{-\infty}^{\infty} \exp \left[-\left(s^{2}+2 \rho s t+t^{2}+2 i u t+2 i v s\right)\right] d t d s=\frac{2 \pi}{\sqrt{1-\rho^{2}}} \exp \left[-\frac{(u+v)^{2}}{4(1+\rho)}-\frac{(u-v)^{2}}{4(1-\rho)}\right] .
$$

Evaluation of $I_{4}$; Noticing that

$$
\frac{\partial I_{4}}{\partial \rho}=-I_{3}=-\frac{2 \pi}{\sqrt{1-\rho^{2}}} \exp \left[-\frac{(u+v)^{2}}{4(1+\rho)}-\frac{(u-v)^{2}}{4(1-\rho)}\right]
$$

and

$$
\left.I_{4}\right|_{\rho=0}=\left[\text { p.v. } \int \frac{1}{s} \exp \left\{-\left(s^{2}+2 i v s\right) / 2\right\} d s\right] \cdot\left[\text { p.v. } \int \frac{1}{t} \exp \left\{-\left(t^{2}+2 i u t\right) / 2\right) d t\right]=J(v) J(u)
$$

where $J(v)=$ p.v. $\int \frac{1}{s} \exp \left\{-\left(s^{2}+2 i v s\right) / 2\right\} d s$ and $J(u)$ is similar.

On the other hand, we have the next three formulations

$$
\begin{aligned}
& \frac{\partial J(v)}{\partial v}=-i \text { p.v. } \int \exp \left\{-\left(s^{2}+2 i v s\right) / 2\right\} d s=-i \sqrt{2 \pi} \exp \left(-v^{2} / 2\right), \\
& J(v)=-i \sqrt{2 \pi} \int_{0}^{v} \exp \left(-x^{2} / 2\right) d x \\
& \left.I_{4}\right|_{\rho=0}=-2 \pi \int_{0}^{u} \exp \left(-x^{2} / 2\right) d x \int_{0}^{v} \exp \left(-x^{2} / 2\right) d x .
\end{aligned}
$$


Hence, we have the next evaluation of $I_{4}$

$$
I_{4}=-2 \pi \int_{0}^{v} \exp \left(-\frac{x^{2}}{2}\right) d x \cdot \int_{0}^{v} \exp \left(-\frac{x^{2}}{2}\right) d x-2 \pi \int_{0}^{\rho} \frac{1}{\sqrt{1-x^{2}}} \exp \left[-\frac{u^{2}-2 u v x+v^{2}}{2\left(1-x^{2}\right)}\right] d x .
$$

Finally we obtain the following lemma for the evaluation of $E[X Y \cdot \operatorname{sgn}(Y-u) \operatorname{sgn}(X-u)]$. (Lemma 2)

$$
\begin{aligned}
I(u, v) & =E[X Y \cdot \operatorname{sgn}(Y-u) \operatorname{sgn}(X-v)]=-\frac{2}{\pi} \rho v \exp \left(-\frac{1}{2} v^{2}\right) \int_{0}^{u} \exp \left(-\frac{1}{2} x^{2}\right) d x \\
& -\frac{2}{\pi} \rho u \exp \left(-\frac{1}{2} u^{2}\right) \int_{0}^{v} \exp \left(-\frac{1}{2} x^{2}\right) d x-\frac{2}{\pi} \rho\left(1-v^{2}\right) \int_{0}^{\rho} \frac{1}{\sqrt{1-x^{2}}} \exp \left[-\frac{u^{2}-2 u v x+v^{2}}{2\left(1-x^{2}\right)}\right] d x \\
& -\frac{2}{\pi} \rho\left(1-u^{2}\right) \int_{0}^{\rho} \frac{1}{\sqrt{1-x^{2}}} \exp \left[-\frac{u^{2}-2 u v x+v^{2}}{2\left(1-x^{2}\right)}\right] d x \\
& +\frac{4}{\pi} \rho v \int_{0}^{\rho} \frac{x(u-v x)}{\left(1-x^{2}\right)^{3 / 2}} \exp \left[-\frac{u^{2}-2 u v x+v^{2}}{2\left(1-x^{2}\right)}\right] d x+\frac{4}{\pi} \rho u \int_{0}^{\rho} \frac{x(v-u x)}{\left(1-x^{2}\right)^{3 / 2}} \exp \left[-\frac{u^{2}-2 u v x+v^{2}}{2\left(1-x^{2}\right)}\right] d x \\
& -\frac{2}{\pi} \rho \int_{0}^{\rho} \frac{x^{2}}{\left(1-x^{2}\right)^{3 / 2}}\left(1-\frac{(u-v x)^{2}}{1-x^{2}}\right) \exp \left[-\frac{u^{2}-2 u v x+v^{2}}{2\left(1-x^{2}\right)}\right] d x \\
& -\frac{2}{\pi} \rho \int_{0}^{\rho} \frac{x^{2}}{\left(1-x^{2}\right)^{3 / 2}}\left(1-\frac{(v-u x)^{2}}{1-x^{2}}\right) \exp \left[-\frac{u^{2}-2 u v x+v^{2}}{2\left(1-x^{2}\right)}\right] d x \\
& +\frac{2}{\pi} \frac{1+\rho^{2}}{\sqrt{1-\rho^{2}}} \exp \left[-\frac{\left.u^{2}-2 u v \rho+v^{2}\right]}{2\left(1-\rho^{2}\right)}\right]+\frac{2}{\pi} \rho \int_{0}^{u} \exp \left(-\frac{2}{\pi} x^{2}\right) d x \int_{0}^{v} \exp \left(-\frac{x^{2}}{2}\right) d x \\
& +\frac{2}{\pi} \rho \int_{0}^{\rho} \frac{1}{\sqrt{1-x^{2}}} \exp \left[-\frac{u^{2}-2 u v x+v^{2}}{2\left(1-x^{2}\right)}\right] d x .
\end{aligned}
$$

By the two lemma 1 and 2 , we can drive the next theorem 1 showing an expression of $E[\tilde{\rho}]^{2}$ as a function of $u, v$ and $\rho$.

(Theorem 1) Under the assumption I and II, we have

$$
\begin{aligned}
E\left[\tilde{\rho}^{2}\right] & =\frac{\pi}{4}\left\{\exp \left(-\frac{u^{2}}{2}\right)+\exp \left(-\frac{v^{2}}{2}\right)\right\}^{-2} \cdot\left\{4 \int_{u}^{\infty} \frac{1}{\sqrt{2 \pi}} \exp \left(-\frac{y^{2}}{2}\right) d y+4 \int_{v}^{\infty} \frac{1}{\sqrt{2 \pi}} \exp \left(-\frac{y^{2}}{2}\right) d y\right. \\
& \left.+4 \frac{\rho^{2}}{\sqrt{2 \pi}} u \exp \left(-\frac{u^{2}}{2}\right)+4 \frac{\rho^{2}}{\sqrt{2 \pi}} v \exp \left(-\frac{v^{2}}{2}\right)+I(u, u)+I(u,-v) I(-v, u)+I(-v,-v)\right\} .
\end{aligned}
$$

We have the following theorem for a fixed $\rho$ by putting $u=v$.

(Theorem 2) Under the assumption I and II, for $-1<\rho<1, u \geqq 0$, we have

$$
\begin{aligned}
\operatorname{Var}[\tilde{\rho}] & =-\rho^{2}+\frac{\pi}{4} \exp \left(u^{2}\right)+\frac{\sqrt{2 \pi}}{4} \rho^{2} u \exp \left(\frac{u^{2}}{2}\right)-\frac{\pi}{2} \exp \left(u^{2}\right) \int_{0}^{u} \frac{1}{\sqrt{2 \pi}} \exp \left(-\frac{x^{2}}{2}\right) d x \\
& +\frac{1}{4} \frac{1+\rho^{2}}{\sqrt{1-\rho^{2}}} \exp \left(u^{2}\right)\left\{\exp \left(-\frac{u^{2}}{1+\rho}\right)+\exp \left(-\frac{u^{2}}{1-\rho}\right)\right\} \\
& -\frac{1}{4} \rho \exp \left(u^{2}\right) \int_{-\rho}^{\rho} \frac{(1+x)\left(1+x^{2}\right)-2 u^{2}(1-x)(1+2 x)^{2}}{\left(1-x^{2}\right)^{3 / 2}(1+x)} \exp \left(-\frac{u^{2}}{1+x}\right) d x
\end{aligned}
$$

In particular for $|\rho|=1$, we have

$$
\operatorname{Var}[\tilde{\rho}]=-1+\sqrt{\frac{\pi}{2}} u \exp \left(\frac{u^{2}}{2}\right)+\pi \exp \left(u^{2}\right) \int_{u}^{\infty} \frac{1}{\sqrt{2 \pi}} \exp \left(-\frac{x^{2}}{2}\right) d x .
$$

Evaluation of $E\left[C_{u, v}(X) C_{u}, v(Y)\right]$; From the relation (A1) we have

$$
\begin{aligned}
& E\left[C_{u}, v(X) C_{u, v}(Y)\right]=\frac{1}{4} E[\operatorname{sgn}(X-u) \operatorname{sgn}(Y-u)+\operatorname{sgn}(X-u) \operatorname{sgn}(Y+v) \\
& +\operatorname{sgn}(X+v) \operatorname{sgn}(Y-u)+\operatorname{sgn}(X+v) \operatorname{sgn}(Y+v)],
\end{aligned}
$$

it is enough to evaluate the term $E[\operatorname{sgn}(X-u) \operatorname{sgn}(Y-u)]$ only. So we have

$$
\begin{gathered}
E[\operatorname{sgn}(X-u) \operatorname{sgn}(Y-v)]=E\left[-\frac{1}{\pi^{2}} \text { p.v. } \int \frac{1}{s} \exp \{i(X-u) s\} \text { ds } \cdot \mathrm{p} \cdot \mathrm{v} \cdot \int \frac{1}{t} \exp \{i(Y-v) t\} d t\right] \\
=-\frac{1}{\pi^{2}} \text { p.v. } \int \mathrm{p} \cdot \mathrm{v} \cdot \int \frac{1}{s t} \exp (-i u s-i v t) E[\exp (i X s+i Y t)] d s d t \\
\quad=-\frac{1}{\pi^{2}} \text { p.v. } \int \mathrm{p} . \mathrm{v} \cdot \int \frac{1}{s t} \exp \left[-\left(t^{2}+2 \rho t s+s^{2}+2 i u s t+2 i v t\right) / 2\right] d s d t
\end{gathered}
$$


which is already given by $I_{4}$. Hence we have (Lemma 3) Under the assumption I and II

$$
\begin{aligned}
& E[\operatorname{sgn}(X-u) \operatorname{sgn}(Y-v)] \\
& \quad=\frac{2}{\pi} \int_{0}^{u} \exp \left(-\frac{x^{2}}{2}\right) d x \int_{0}^{v} \exp \left(-\frac{x^{2}}{2}\right) d x \\
& \quad+\frac{2}{\pi} \int_{0}^{\rho} \frac{1}{\sqrt{1-x^{2}}} \exp \left[-\frac{u^{2}-2 u v x+v^{2}}{2\left(1-x^{2}\right)}\right] d x
\end{aligned}
$$

(Theorem 3) Under assumption I and II

$$
\begin{aligned}
& E\left[C_{u \cdot v}(X) C_{u, v}(Y)\right] \\
& \quad=\frac{1}{4}\{J(u, u)+J(u,-v)+J(-v, u) \\
& \quad+J(-v,-v)\}
\end{aligned}
$$

where $J(u, v)=E[\operatorname{sgn}(X-u) \operatorname{sgn}(Y-v)]$ which is given in Lemma 3.

In particular for the case $u=v$, we have

$$
\begin{aligned}
& E\left[C_{u}(X) C_{u}(Y)\right] \\
& \quad=\frac{1}{\pi} \int_{-\rho}^{\rho} \frac{1}{\sqrt{1-x^{2}}} \exp \left(-\frac{u^{2}}{1+x}\right) d x .
\end{aligned}
$$

From the above theorem 3, it may be actually possible to estimate $\rho(h)$ of a Gaussian process corresponding to the realization of hard limiting process. Estimates can be obtained by the use of the numerical table or its graph of the function of $\rho$ being computed by the right hand of the equation (A14) or (A15) beforehand.

\section{References}

Fairbridge, R. W. 1961: Convergence of evidence on climatic changes and ice ages, Ann. New York Academy of Sci., 95, Art 1, 543-579.

Huzii, M. 1963: On a simplified method of the estimation of the correlogram for a stationary Gaussian process. Ann. Inst. Statist. Math., 14, 259-269.

— 1974 : Time series analysis (in Japanese), Corona-sha, Tokyo, 137-138.

Inagaki, N. and M. Kondo, 1980: Several estimators of the autocorrelation based on limited estimating functions for a stationary Gaussian process. J. Japan Statist. Soc., 11, 1-15.

Kai, K. 1979: Collection of curves of climatic variation since A.D. 1200(I). In Studies on Climatic Variation (in Japanese). Report of Climatology and Meteorology, Institute of Geoscience, Univ. Tsukuba (4), 24-37.

Kedem, B. 1980: Estimation of the parameters in stationary autoregressive processes after hard limiting. J. Amer. Statist. Soc., 75, 146-153.

Nemoto, J. and T. Asakura, 1980: Climatic change and long range forecasting (in Japanese). Asakura-shoten, Tokyo, $202 \mathrm{pp}$.

Takahashi, T. 1979: Climatic change and social variation. Saigai no kenkyu, 10, 93-103 (in Japanese)

Yamamoto, G., 1979: Climatic variation (in Japanese), Tokyo Univ. Press, Tokyo, 206 pp.

\title{
数個の気候時系列の特徵を刈込み操作で表わした統計的指数
}

\author{
岡本雅 典 \\ 広島大学経済学部

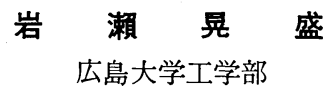

太陽黒点数を含むいくつかの単位の異なる気候変動時系列に共通する特徵を総合的に示す統計的指数を作るた め，もとの時系列をレベル切断による刈込み系列 (hard limiting series) 飞変換し，これらの総和系列として指 数を与えた。時間的変化の同時生起に対する弱い規準を与えて，1200１900年にわたる 7 個の気候変動の時系列 データに対してこのような総和系列を分析した結果, 著しい寒冷な期期 (Maunder Minimum) と温暖な期期を 指数の変化によって表現することができた。 また海面水位，年輪中の ${ }^{14} \mathrm{C}$ ，太陽黒点数の長年変化と比較した。 これらの比較から，この指数系列は使用した原系列の各特徵を同時に保存しているよらに見える。

このような指数の統計的性質を知るために，その相異なる 2 時点間の相関係数（自己相関係数）の不偏推定量 を定式化し，この推定量の分散を最小化するような切断を最適な切断レベルとした。さらに指数の共分散関数は 切断レベルと 2 時点間の母相関係数の陽表的かつ数值計算可能な積分関数で表わされることを示した。また上記 の母相関係数をその不偏推定値で代用して求めた積分関数值と指数の共分散関数との差の平均的大きさは概して 小さく，その差の平均と分散を共分散関数の各ラグに対して示した。 